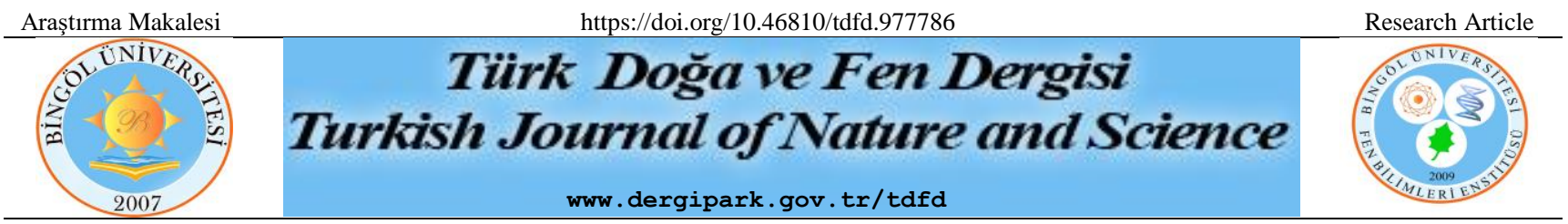

\title{
Görüntü Bölütleme İçin Fourier Dönüşümü, Hessian Matris Ve Özdeğerler Kullanılarak Yeni Bir Aktif Kontur Modeli
}

\author{
Kazım HANBAY ${ }^{1^{*}}$ \\ ${ }^{1}$ İnönü Üniversitesi, Mühendislik Fakültesi, Yazılım Mühendisliği Bölümü, Malatya, Türkiye \\ Kazım HANBAY ORCID No: 0000-0003-1374-1417 \\ *Sorumlu yazar: kazimhanbay@gmail.com
}

(Alınış: 02.08.2021, Kabul: 09.08.2021, Online Yayınlanma: 31.12.2021)

\begin{abstract}
Anahtar
Kelimeler

Aktif kontur

modeli,

Görüntü

bölütleme,

Fourier

dönüşümü,

Hessian

matrisi

Öz: Aktif kontur model nesne sınırlarını bölütleyebilir ve bu yüzden görüntü analizinde ve bölütlemesinde kullanılmaktadır. Frekans bilgisi ve yüksek mertebe diferansiyel hesaplamalar içermeyen mevcut aktif kontur modelleri yoğunluk eşitsizliği ve gürültü içeren bazı görüntüleri bölütlerken başarısızdır. Bu çalışmada mevcut Hessian matris ve özdeğer temelli metot içerisine Fourier dönüşümü entegre edilerek yeni bir aktif kontur modeli geliştirilmiştir. Giriş görüntüsünün Fourier dönüşümü hesaplanmış ve düzey küme fonksiyonunda aktif bir şekilde kullanılmıştır. Sonuçta frekans alanında elde edilen piksel yoğunluk bilgisinin diferansiyel analizi gerçekleştirilmiştir. Ayrıca piksel analizinin uzaysal bilgi içerdiği mevcut Hessian matris ve özdeğer temelli metottan farklı olarak, bu yeni model değişmez Fourier alanında sınır piksel bileşenlerini tespit etmeyi amaçlamaktadır. Geliştirilen model mevcut Hessian matris ve özdeğer temelli metot ve LIF metodu ile karşılaştırılmıştır. Deneysel sonuçlar önerilen metodun düşük iterasyon ve yüksek bölütleme doğruluğu ile daha iyi bölütleme performansını elde edebildiğini göstermiştir.
\end{abstract}

\section{A New Active Contour Model Using Fourier Transform, Hessian Matrix And Eigenvalues For Image Segmentation}

Keywords
Active
contour
model,
Image
segmentation,
Fourier
transform,
Hessian
matrix

\begin{abstract}
Active contour model can segment object boundaries and thus it has been used in image analysis and segmentation. Current active contour models without frequency information and highorder differential computations fail when segmenting some images containing intensity inhomogeneity and noise. In this paper, a new active contour model has been developed by integrating the Fourier transform into the existing Hessian matrix and eigenvalue-based method. The Fourier transform of the input image is calculated and used actively in the level set function. As a result, differential analysis of the pixel density information obtained in the frequency domain has also performed. Also, unlike the current Hessian matrix and eigenvalue-based method where the pixel analysis contains the spatial information, this new model aim to detect the boundary pixel components in the invariant Fourier domain. The developed method is compared with existing Hessian matrix and eigenvalue-based method and LIF method. Experimental results show that the proposed method can achieve a better segmentation performance with less iterations and high segmentation accuracy.
\end{abstract}

\section{GİRIŞ}

Görüntü bölütleme bilgisayar görmesi ve görüntü işleme ve alanlarında yaygın şekilde kullanılmaktadır. Görüntü işleme uygulamalarının özel alanlarında bölütleme yapılarak anlamlı bilgi çıkarımı yapılabilmektedir. Kass ve ark. [1] tarafından geliştirilen aktif kontur yöntemi popüler görüntü bölütleme yöntemleri arasında yer almakta olup oldukça zorlu problemlerde etkin sonuçlar üretmektedir. Aktif kontur yöntemi görüntülerdeki nesnelerin kenarlarını tespit ederek farklı nesneleri bulan bir yöntemdir. $\mathrm{Bu}$ yöntemde öncelikle nesnelerin etrafinda onları çevreleyen bir şerit oluşturulur. Algoritmanın ilerleyişine paralel şekilde şeridi oluşturan noktalar nesneye doğru yaklaşarak nesnenin kenarları üzerinde dururlar. Böylece nesnelerin kenar bölgeleri tespit edilmiş olur. 
Aktif kontur modelleri kenar temelli modeller [2,3] ve bölge tabanlı modeller [4-6] olmak üzere genel olarak iki ana sınıfta incelenmektedir. Kenar temelli yöntemler arasında en bilineni geodezik aktif kontur yöntemidir [7]. $\mathrm{Bu}$ yöntemde kenarlar gradyan büyüklügüune göre tespit edilmektedir. Ancak bu yöntem gürültüden etkilenmektedir. Bölge temelli aktif kontur yöntemleri ise genellikle düzey kümesi (level set) yöntemini kullanmaktadırlar [8,9]. CV yöntemi bu yöntemler arasında en bilinenidir [6]. Bu yöntemlerde eğrinin iç ve dıș gölgesinde kalan enerji tanımlanır. Enerji minimum değere ulaştığında elde edilen eğri nesnenin sınırı olarak tanımlanır. $\mathrm{Bu}$ yöntemdeki enerji hesaplamalarını iyileştirmek için farklı yaklaşımlar geliştirilmiştir [10,11]. Böylece CV yönteminin gürültü hassasiyeti ve çalışma hızı iyileştirilmiştir. Yine kontur iç bölgesinin düzensiz olduğu görüntülerde daha iyi bölütleme elde etmek için yumuşak kontur bölütlemesi yapabilen çalışmalar geliştirilmiştir [12]. Diğer bir çalışmada ise düzey küme fonksiyonu güncellenmesinde düzenlenmiş Heaviside ve Dirac delta fonksiyonları kullanılmıștır [13]. Böylece bölge temelli bölütleme yöntemlerinin özellikle çalışma hızı iyileştirilmiştir. Kenar bölgelerindeki gürültü etkisini azaltmak için tasarlanan bir aktif kontur yönteminde ise bölgesel benzerlik faktörü geliştirilmiştir [14]. Böylece komşu piksellerin benzerlik değerleri analiz edilerek gürültü bileșenleri elenmiştir. Görüntü içerisinde farklı görünüş davranışlarına sahip bölgeleri tespit ederek bölütlenmelerini sağlamak için kaskat öğrenme metodu geliştirilmiştir [15]. Bu yöntemde ilgilenilen bölgenin şekil bilgisi ile yine aynı bölgenin görünüş bilgilerinin olasılıksal modeli düzey küme fonksiyonu içerisinde birlikte kullanılmıstır. Ancak bu yöntem renk bağımlı çalışmakta olup görüntülerde olabilecek farklı renk bölgelerinde istenen sonucu vermemektedir.

Yukarıda bahsedilen literatür çalışmalarında yöntemlerin gürültüye karşı zayıflıkları, yüksek çalışma zamanları ve renk farklılıklarında elde ettikleri düşük başarılar göze çarpan temel eksiklikler olarak öne çıkmaktadır. Bu noktalardan hareketle, bu çalışmada hızlı, yüksek bölütleme doğruluğuna sahip ve düzgün obje sinırları elde edebilen yeni bir aktif kontur yöntemi geliştirilmiştir. Geliştirilen bölge temelli bölütleme yönteminde literatürde daha önce geliştirilen bir yöntem içerisine Fourier dönüşümü entegre edilerek yöntemin frekans alanına taşınması sağlanmıştır. Böylece bazı görüntülerde özdeğer matrisi ile elde edilemeyen ancak gerekli olan önemli bölgesel frekans bileşenleri tespit edilerek yöntemin düzey küme fonksiyonunun davranışı iyileştirilmiştir.

Çalışma şu şekilde organize edilmiştir: Bölüm 2'de literatürde daha önce geliştirilen bölge temelli aktif kontur yönteminin önemli adımları sunulmuştur. Bölüm 3'te geliștirilen Fourier dönüşümü temelli yeni yöntem detaylandırılmıştır. Bölüm 4'te yöntemin bölütleme sonuçları karşılaştırmalı şekilde irdelenmiştir. Bölüm 5 'te ise elde edilen sonuçlar tartışılmıştır.

\section{HESSIAN MATRISII VE ÖZDEĞER TEMELLİ AKTIF KONTUR YÖNTEMI}

Görüntülerde türev hesaplamalarında kullanılan gradyan bilgisi yerine ikinci mertebe türev hesaplamaları kullanılarak kenar ve köșe gibi değişim ifade eden bilgiler elde edilebilmektedir. Bu noktadan hareketle aktif kontur yöntemleri içerisinde gradyan hesaplaması yerine görüntünün Hessian matrisi hesaplanarak elde edilen özdeğer bilgileri ile etkili bölütleme yöntemleri geliştirilmiștir [3]. Özdeğer bilgilerini kullanmaya dayanan bu yöntemde iç ve dış konturların yoğunluk bilgileri düzey kümesi metodu kullanılarak hesaplanmaktadır. Bunun için öncelikle bir I görüntüsünün birinci ve ikinci mertebeden türevleri hesaplanarak Hessian matrisi aşağıdaki gibi hesaplanmışırır $[3,16]$ :

$$
\mathcal{H}(x, y)=\left(\begin{array}{cc}
\frac{\partial^{2}}{\partial x^{2}} I(x, y) & \frac{\partial^{2}}{\partial x \partial y} I(x, y) \\
\frac{\partial^{2}}{\partial y \partial x} I(x, y) & \frac{\partial^{2}}{\partial y^{2}} I(x, y)
\end{array}\right)=\left[\begin{array}{ll}
D_{x x} & D_{x y} \\
D_{x y} & D_{y y}
\end{array}\right]
$$

Burada $D_{x x}, D_{y y}$ ve $D_{x y}$ görüntünün sirasiyla ikinci mertebeden yatay, dikey ve diagonal türevlerini göstermektedir. Hesaplanan Hessian matrisi kullanılarak görüntünün özdeğer matrisleri aşağıdaki gibi hesaplanır:

$$
\begin{aligned}
& \lambda_{1}=\frac{1}{2}\left(D_{x x}+D_{y y}-\sqrt{-2 D_{x x} D_{y y}+D_{x x}{ }^{2}+4 D_{x y}{ }^{2}+D_{y y}{ }^{2}}\right) \\
& \lambda_{2}=\frac{1}{2}\left(D_{x x}+D_{y y}+\sqrt{-2 D_{x x} D_{y y}+D_{x x}{ }^{2}+4 D_{x y}{ }^{2}+D_{y y}{ }^{2}}\right)
\end{aligned}
$$

Burada $\lambda_{1}$ ve $\lambda_{2}$ özdeğer matrisleridir. $\mathrm{Bu}$ bilgiler görüntü için bir defa hesaplandıktan sonra aşağıdaki enerji fonksiyonunu minimize etmek için kullanılmıştır:

$$
\begin{gathered}
E\left(c_{1}, c_{2}, C\right)= \\
\int_{\text {inside }(C)}\left|I(x)-c_{1}\right| d x+\int_{\text {outside }(C)} \mid I(x)- \\
c_{2} \mid d x, \quad x \in \Omega
\end{gathered}
$$

Burada $I(x): \Omega \rightarrow \mathbb{R}$ and $C:[0,1] \rightarrow \Omega$ parametre edilmiş bir düzlemsel (planar) eğriyi tanımlamaktadır. $C$ konturu $I$ görüntüsünü birbiri ile örtüşmeyen iki bölgeye ayırmaktadır. Enerji fonksiyonu $c_{1}$ ve $c_{2}$ terimleri açısından minimize edilerek optimal $c_{1}$ ve $c_{2}$ bilgileri elde edilir. Bu noktada görüntünün özdeğer matrisleri enerji fonksiyonuna aşağıdaki gibi entegre edilerek doğru obje sınırını ifade eden aktif kontur eğrisi elde edilmiştir:

$$
\begin{aligned}
& E\left(c_{1}, c_{2}, C\right) \\
& =\int_{\text {inside }(C)} \frac{I(x)-\frac{c_{1}+c_{2}}{2}}{\max \left(\left|I(x)-\frac{c_{1}+c_{2}}{2}\right|\right)} d x \\
& \left.+\int_{\text {outside }(C)}\left|\frac{I(x)-\frac{c_{1}+c_{2}}{2}}{\max \left(\left|I(x)-\frac{c_{1}+c_{2}}{2}\right|\right)}\right| d x\right)|\operatorname{eig}(\mathcal{H}(I(x)))|
\end{aligned}
$$

Burada $|e i g(\mathcal{H}(I(x)))| \quad I$ görüntüsünün Hessian matrisinin özdeğerlerini ifade etmektedir. Özdeğer bilgilerinin enerji fonksiyonunda kullanılmasiyla $E\left(c_{1}, c_{2}, C\right)$ fonksiyonu Lipschitz fonksiyonuna göre $(\phi)$ 
minimize edilir ve böylece gradyan azaltma akışı (gradient descent flow) aşağıdaki ifade ile hesaplanmış olur:

$$
\frac{\vartheta \phi(x, t)}{\vartheta t}=H(\operatorname{spf}(I(x)) \cdot|\operatorname{eig}(\mathcal{H}(I(x)))|)
$$

Burada $s p f$ fonksiyonu başlangıç konturu kullanarak nesne kenarlarını hesaplamaya yardımcı olurken, $\mid$ eig $(\mathcal{H}(I(x))) \mid$ ifadesi ile de özdeğer matrislerinin büyüklük bilgisi kullanılarak özellikle nesne kenarlarının ortaya çıkarılması hedeflenmiştir. Çünkü görüntüdeki farklı nesnelerin kenar ve köşe bilgileri özdeğer bilgileri ile etkin bir şekilde ortaya çıkartılmıştır. Piksel değişimleri enerji fonksiyonuna özdeğerler ile verildiği için, başlangıç aktif konturunun iteratif bir şekilde ilerleyişi esnasında konturun kenar bölgelerine hızlı yakınsama yapması sağlanmıştır.

$\mathrm{Bu}$ yöntem birçok görüntüde oldukça iyi sonuçlar üretmiştir. Bununla birlikte sınıf içi farklılıkların az olduğu ve nesne sınırlarının gürültülü olduğu bazı görüntülerde istenen sonuçları verememektedir. Ayrıca iteratif kontur bulma sürecinde nesnelerin kenar bölgelerinin frekans alanı temsil bilgilerinin sürece dahil edilmediği görülmektedir. $\mathrm{Bu}$ nedenle geliştirilen bu yöntem bazı görüntülerde istenen sonucu vermemektedir.

\section{3. ÖNERİLEN YÖNTEM}

Fourier dönüşümü zaman alanındaki bir sinyali frekans alanına dönüştürmek için kullanılmaktadır [17-18]. Böylece sinyalin anlaşılmasını sağlayarak anlamlı bilgiler çıkartılması amaçlanmıştır. Bir sinyalin öteleme ve ölçekleme gibi parametrelerden bağımsız bir şekilde analiz edilebilmesi Fourier dönüşümünün sağladığ1 önemli avantajlardandır. Görüntülerinde benzer şekilde Fourier dönüşümleri hesaplanarak frekans alanındaki lokal ve bölgesel piksel davranışları analiz edilebilmektedir. Fourier dönüşümünün daha etkin ve hızlı yapılabilmesi içi hızlı fourier dönüşümü (FFT) kullanılmaktadır [18].

$M \times N$ boyutundaki bir $I$ giriş görüntüsünün Fourier dönüşümü Eşitlik 7 kullanılarak aşağıdaki gibi hesaplanmaktadır:

$$
F(u, v)=\sum_{x=0}^{M-1} \sum_{y=0}^{N-1} I(x, y) \times e^{-j 2 \pi(u x+v y) / N}
$$

Fourier dönüşümü ile görüntünün pikselleri frekans alanına dönüştürülmektedir. Yapılan çalışmalarda Fourier dönüşümü ile elde edilen gerek frekans spektrumu gerekse faz spektrumu kullanılarak görüntülerdeki önemli olabilecek bilgiler çıkartılıp analiz edilebilmektedir.

$\mathrm{Bu}$ çalışmada kaynak [3]'teki aktif kontur yöntemine önemli bir yenilikçi yaklaşım kazandırılması amaçlanmıştır. $\mathrm{Bu}$ kapsamda bölütlenecek görüntünün öncelikle bir defaya mahsus FFT'si hesaplanarak bölütlenecek bölgelerin frekans bileşenlerinin enerji fonksiyonuna aktif şekilde dahil edilmesi amaçlanmıştır. Böylece ham giriş görüntüsünün Hessian matrisi ve özdeğerlerini hesaplamak yerine, giriş görüntüsünün Fourier dönüşümünün Hessian matrisi ve özdeğerleri hesaplanmıştır. Böylece görüntüde olabilecek dönme, örtüşme ve gürültü gibi durumlardan minimum etkilen bir yöntem geliştirilmesi hedeflenmiştir. Geliştirilen yöntemin temel adımları şu şekildedir:

Adım 1: Düzey küme fonksiyonu aşağıdaki gibi tanımlanarak başlatılır:

$$
\phi(x, t=0)=\left\{\begin{array}{cl}
1, & x \in \Omega_{0} \\
-1, & x \in \Omega-\Omega_{0}
\end{array}\right.
$$

Burada $\Omega_{0}$ görüntü $\Omega$ nın bir alt kümesini gösterir.

Adım 2: Giriş görüntüsünün FFT'si $F(u, v)$ hesapanır.

Adım 3: Eşitlik 1 kullanılarak $F(u, v)$ 'nin Hessian matrisi hesaplanır.

Adım 4: Eşitlik 2 ve Eşitlik 3 kullanılarak Hessian’nın $\lambda_{1}$ ve $\lambda_{2}$ özdeğer matrisleri hesaplanır.

Adım 5: Özdeğerlerin büyüklük bilgisi $u(x)=$ $|\operatorname{eig}(\mathcal{H}(F(u, v)))|=\sqrt{\lambda_{1}{ }^{2}+\lambda_{2}{ }^{2}}$ ifadesi ile hesaplanır.

Adım 6: Enerji fonksiyonu $E\left(c_{1}, c_{2}, C\right)$ Eşitlik 5'teki ifade kullanılarak iteratif şekilde alt işlemler olarak şu şekilde minimize edilir.

Adım 6.1: $\left|\phi^{k+1}-\phi^{k}\right|>0$, burada $k$ iterasyon sayısıdır.

Adım 6.2: $c_{1}(\phi)$ ve $c_{2}(\phi)$ fonksiyonları hesaplanır [3].

Adım 6.3: $s p f$ fonksiyonu $\operatorname{spf}(I(x))=\frac{I(x)-\frac{c_{1}+c_{2}}{2}}{\max \left(\left|I(x)-\frac{c_{1}+c_{2}}{2}\right|\right)}$ ifadesi ile hesaplanır.

Adım 6.4: Eşitlik 6'daki düzey küme fonksiyonu kullanılarak düzey küme fonksiyonu değerlendirilir. $\mathrm{Bu}$ çalışmada düzey küme fonksiyonu aşağıdaki gibi düzenlenerek görüntünün Fourier dönüşümü $F(u, v)$ bilgisi düzey küme fonksiyonunda iteratif olarak kullanılmıştır:

$$
\frac{\vartheta \phi(x, t)}{\vartheta t}=H(\operatorname{spf}(I(x)) \cdot|\operatorname{eig}(\mathcal{H}(F(u, v)))|)
$$

Adım 6.5: $\phi(x)$ fonksiyonu güncellenir.

Adım 7: Eğer düzey küme fonksiyonu istenilen düzeyde optimize edilmişse iterasyon sonlandırılır.

Önerilen yöntemin temel adımlarındaki en önemli fark Fourier dönüşümü $F(u, v)$ bilgisinin düzey küme fonksiyonuna entegre edilmesi ve böylece enerji 
minimize etme sürecinde görüntünün frekans bileşenlerinden faydalanılmasıdır. Böylece lokal piksel davranışlarının türeve dayalı değişim bilgileri uzaysal alan yerine frekans alanında yapılmıştır. Giriş görüntüsü frekans alanına taşınarak nesnelerin kenar bölgelerinde meydana gelen piksel yoğunluk bilgilerinin değişimleri hassas bir şekilde kodlanmıştır. Aktif konturun iç ve dış bölgelerindeki enerji hızlı bir şekilde hesaplanmış ve $s p f$ fonksiyonun daha güvenli bir aralıkta çalışması sağlanmıştır. Böylece düzey küme fonksiyonu optimal değerlere hızlı şekilde ulaşmıştır.

Fourier dönüşümü ile özdeğer hesaplamalarının hibrit şekilde kullanılması aktif kontur literatüründe yenilikçi bir bakış açısı olarak değerlendirilmektedir. Fourier dönüşümünün sahip olduğu özelliklerin yanı sıra, özdeğerlerin dönme ve ölçekleme gibi durumlardan bağımsız olarak etkili sonuçlar vermesi dikkate değer bir etkinlik sağlamıştır. Bu durum özellikle konkav ve konveks obje sınırlarında istenen doğrulukta bölütleme sonuçları elde edilebilmiştir. Nesne kenarlar bölgelerinin geometrik olarak düz, konkav, konveks veya vadi görünümlü olması yöntemin çalışmasını etkilememiştir. Çünkü özdeğerler genellikle bu tip bölgelerdeki piksel yoğunluk değişimini arka plandan ve komşu bölgelerden ayırt edebilecek geometrik özelliklere sahiptir.

\section{DENEYSEL SONUÇLAR}

$\mathrm{Bu}$ bölümde geliştirilen FFT temelli aktif kontur modelinin bölütleme sonuçları diğer yöntemlerle karşılaştırılarak verilmiştir. Değerlendirme ölçütü olarak bölütleme doğruluğu kullanılmıştır. Kullanılan görüntüler aktif kontur çalışmalarında sıklıkla kullanılan medikal görüntüler ve diğer bazı bilinen görüntülerdir. Önerilen yöntem iki farklı güncel yöntem ile karşılaştırılmıştır. İlk yöntem Bölüm 2'de detayları verilen ve geliştirilen yöntemin ele alarak bölütleme performansını arttırdığ 1 bölge temelli aktif kontur yöntemidir [3]. İkinci yöntem ise LIF yöntemi olarak adlandırılan ve bölgesel kontur enerjisi hesaplamasına dayanan yöntemdir [4]. Bölütleme yöntemlerinin sonuçlarını metrik olarak karşılaştırmak için Figure of Merit olarak bilinen FOM hesaplaması kullanılmıștır [19]. FOM değeri 1 ise bölütleme yöntemi ideal bölütleme ile aynı sonucu üretmiş ve en doğru sonucu elde etmiş demektir. Metrik sonuçların karşılaştırıldığı ilgili tablolarda en iyi değerler koyu font olarak belirtilmiştir.

İlk uygulama renkli bir görüntü üzerinde gerçekleștirilmiștir. Bölütleme sonuçları Şekil 1'de görülmektedir. Önerilen yeni yöntem FFT ile geliştirmiş olduğu mevcut Hessian-özdeğer temelli yöntemin sonuçlarını iyileştirmiştir. Görüntüdeki 4 rakamının iç ve dış gölge sınırlarını doğru şekilde tespit edebilmiştir. Özellikle dış bölge konturlarının tespit edilebilmesi $s p f$ ve enerji fonksiyonunun frekans alanı bilgileri ile daha etkin çalıştığının göstergesidir. Orijinal Hessian-özdeğer temelli yöntem ise dış bölge sınırlarını çift kontur şeklinde bulmuştur. LIF yöntemi ise hem süre hem de bölütleme doğruluğu açısından en kötü sonuçları üretmiștir. Hem iç bölge hem de dış bölge sınırları pürüzlü ve doğru değildir.

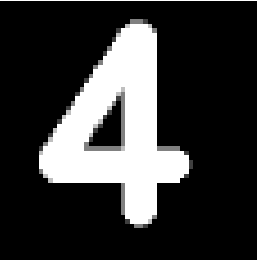

Orijinal görüntü

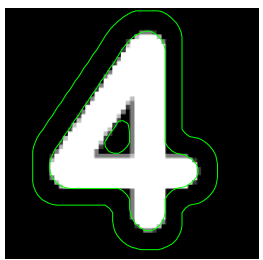

Orijinal Hessian-Özdeğer Yöntemi

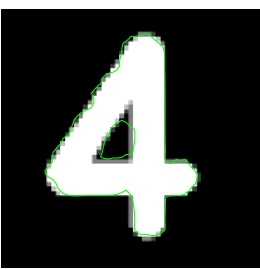

LIF

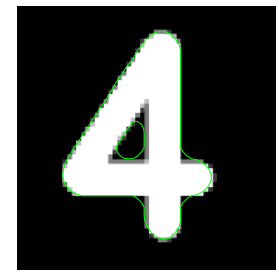

Önerilen FFT temelli

Hessian-Özdeğer Yöntemi
Şekil 1. Renkli görüntü için yöntemlerin bölütleme sonuçları

Aktif kontur temelli bölütleme yapan yöntemler bu konturları enerji fonksiyonunu iteratif olarak minimize ederek hesaplamaktadır. $\mathrm{Bu}$ nedenle karşılaştırma çalışmalarında yöntemlerin aktif kontur üretme sürecini kaç iterasyonda ve ne kadar sürede (saniye) tamamladıkları da önemli bir parametredir. Yine üretilen bölütleme sonuçlarının gerçek bölütleme ile olan benzerliğinin metrik olarak ölçülmesi için FOM sonuçlarına da yer verilmiştir. Bu nedenle Tablo 1'de Şekil 1'de görülen sonuçlar için yöntemlerin iterasyon sayıları ve çalışma zamanları verilmiştir. LIF yönteminin en iyi sonuçları üretmesi için optimal iterasyon sayısı 600 olarak sabitlenmiştir. Ancak buna rağmen istenen sonuçlara ulaşamamıştır. Orijinal Hessian-özdeğer yöntemi geliştirilen yeni yönteme göre daha düşük iterasyon sayısına ve çalışma süresine sahip olmasına rağmen bölütleme doğruluğu açısından daha düşük FOM değerine sahiptir.

Tablo 1. Sekil 1'deki sonuçlar için yöntemlerin iterasyon sayılarının, çalışma sürelerinin ve FOM değerlerinin karşılaştırılması

\begin{tabular}{cccc}
\hline Yöntemler & $\begin{array}{c}\text { İterasyon } \\
\text { sayısı }\end{array}$ & Süre & FOM \\
\hline LIF & 600 & 8.263 & 0.738 \\
$\begin{array}{c}\text { Orijinal Hessian-Özdeğer } \\
\text { Yöntemi }\end{array}$ & $\mathbf{2}$ & $\mathbf{0 . 1 7 5}$ & 0.138 \\
$\begin{array}{c}\text { Önerilen FFT temelli } \\
\text { Hessian-Özdeğer Yöntemi }\end{array}$ & 3 & 0.214 & $\mathbf{0 . 7 4 2}$ \\
\hline
\end{tabular}

Yapılan ikinci uygulamada ise medikal bir görüntü kullanılarak yöntemin performansı incelenmiștir. Bilgisayarlı tomografi (BT) ile elde edilen akciğer görüntüsünde önerilen yöntem akciğer sınırlarını ve iç bölgelerini aşırı bölütleme yapmadan bulabilmiștir. Orijinal Hessian-özdeğer yöntemi ise iç bölgelerde kısmen aşırı bölütleme yapmıştır. LIF yöntemi ise hem akciğer sınırlarını pürüzlü bulmuş hem de iç bölgelerde ve görüntünün farklı bölgelerinde yanlış ve aşırı bölütleme gerçekleştirmiştir. 

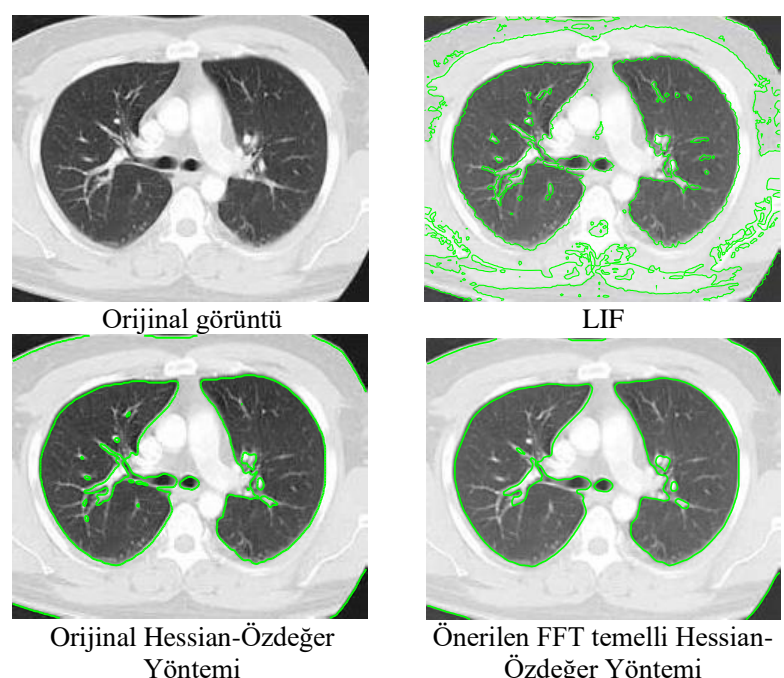

Özdeğer Yöntemi

Sekil 2. Akciğer BT görüntüsü için yöntemlerin bölütleme sonuçları

Akciğer BT görüntüsü için yöntemlerin metrik olarak karşılaştırılması Tablo 2'de verilmiştir. Şekil 1'deki uygulamada olduğu gibi orijinal Hessian-özdeğer yöntemi daha düşük iterasyon sayısına ve çalışma zamanına sahip olmakla birlikte medikal uygulamalarda önemli olan bölütleme doğruluğu ve hassasiyeti açısından daha düşük FOM değerine sahiptir. LIF yöntemi ise her 3 parametre açısından en kötü yöntemdir.

Tablo 2. Şekil 2'deki sonuçlar için yöntemlerin iterasyon sayılarının, çalışma sürelerinin ve FOM değerlerinin karșılaștırılması

\begin{tabular}{cccc}
\hline Yöntemler & $\begin{array}{c}\text { İterasyon } \\
\text { sayısı }\end{array}$ & Süre & FOM \\
\hline LIF & 600 & 38.74 & 0.320 \\
Orijinal Hessian-Özdeğer & 4 & 0.324 & 0.624 \\
$\begin{array}{c}\text { Yöntemi } \\
\text { Önerilen FFT temelli }\end{array}$ & 4 & 0.358 & 0.701 \\
Hessian-Özdeğer Yöntemi & & & \\
\hline
\end{tabular}

Diğer bir uygulama ise yine bir medikal görüntü olan karaciğer BT görüntüsü üzerinde yapılmıştır. Geliştirilen yeni yöntem orijinal yöntemin aşırı bölütlemesini düzelterek karaciğer konturlarını daha yumuşak ve örtüşme problemi olmadan bulmuştur. Özellikle karaciğer boyutunun metrik olarak hesaplanması gereken teşhis ve tedavi uygulamalarında bu FFT temelli yeni yöntem ile karaciğer boyutları daha doğru bir şekilde hesaplanabilir. Yine görüntülerde olabilen ve görüntü içeriği ile ilgisi olmayan alt bölgeleri görmezden gelinmiştir. Ancak LIF ve orijinal Hessian-özdeğer yöntemi bu bölgeleri de bölütlemeye çalışmıștır.

Tablo 3'te Şekil 3'te elde edilen bölütleme sonuçlarına ait metrik ölçümler verilmiştir. Diğer sonuçlara benzer şekilde önerilen yeni yöntem en yüksek bölütleme doğruluğuna sahip olmakla beraber makul iterasyon sayısına ve çalışma süresine sahiptir. LIF yöntemi hem süre hem de FOM değeri açısından en kötü yöntemdir.

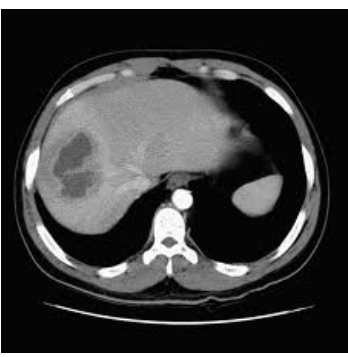

Orijinal görüntü

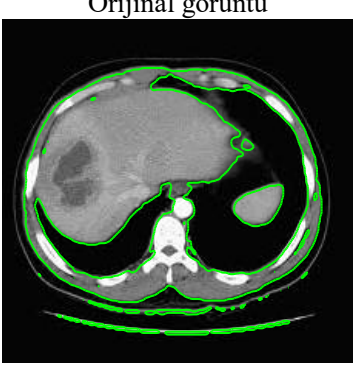

Orijinal Hessian-Özdeğer Yöntemi

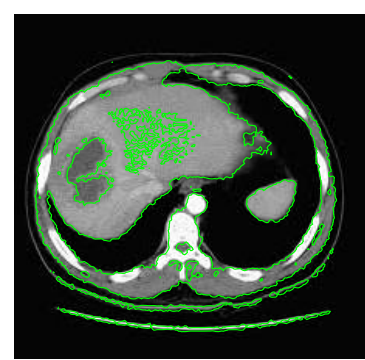

LIF

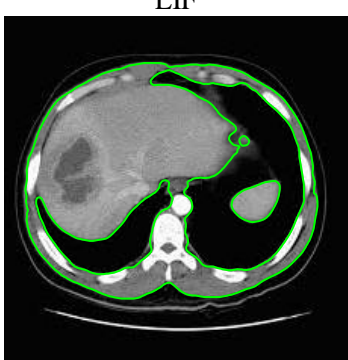

Önerilen FFT temelli HessianÖzdeğer Yöntemi
Şekil 3. Karaciğer BT görüntüsü için yöntemlerin bölütleme sonuçları

Tablo 3. Şekil 3'teki sonuçlar için yöntemlerin iterasyon sayılarının, çalışma sürelerinin ve FOM değerlerinin karşılaştırılması

\begin{tabular}{|c|c|c|c|}
\hline Yöntemler & $\begin{array}{c}\text { İterasyon } \\
\text { sayısı }\end{array}$ & Süre & FOM \\
\hline LIF & 600 & 42.59 & 0.425 \\
\hline $\begin{array}{c}\text { Orijinal Hessian-Özdeğer } \\
\text { Yöntemi }\end{array}$ & 5 & 1.597 & 0.542 \\
\hline $\begin{array}{c}\text { Önerilen FFT temelli } \\
\text { Hessian-Özdeğer Yöntemi }\end{array}$ & 5 & 1.783 & 0.685 \\
\hline
\end{tabular}

\section{SONUÇLAR VE TARTIŞMA}

$\mathrm{Bu}$ çalışmada uzaysal alanda çalışan mevcut Hessian matrisi ve özdeğer bilgilerini kullanan aktif kontur yöntemine Fourier dönüşümü ile farklı bir yetkinlik kazandıran yeni bir aktif kontur yöntemi geliştirilmiştir. Geliştirilen yöntemde giriş görüntüsü frekans alanına dönüştürülerek gerekli tüm Hessian ve özdeğer hesaplamaları bu alanda yapılmıştır. Böylece edilebilmesi spf ve enerji fonksiyonlarının görüntünün frekans bileșenlerinden elde edilen piksel yoğunluk bilgileri ile etkili sonuçlar üretmesi hedeflenmiştir. Geliştirilen yöntem nesne sınırlarını ele alınan orijinal yönteme göre daha iyi tespit edebilmiștir. Özellikle aşırı bölütleme sorunu giderilmiștir. Yeni yöntem iterasyon sayısı ve çalışma zamanı olarak orijinal yönteme göre kısmen maliyetli olmakla beraber bölütleme doğruluğu daha iyidir. Karşılaştırma sonuçlarına göre yeni yöntem literatürdeki LIF yöntemine göre de tüm parametreler açısından üstünlük sağlamıştır.

Bununla birlikte geliștirilen yöntemin zayıf nesne kenarlarının arka plandan ayırt edilmesinde kısmi olarak eksiklikleri bulunmaktadır. Nesne kenarlarında özdeğer bilgilerinin analitik olarak piksel bazlı yorumlanması ile bu eksikliğin giderileceği düşünülmektedir. Gelecekte bu yönde çalışmalar yürütülmesi planlanmaktadır. Ayrıca diğer frekans alanı dönüşümlerinin Hessian ve özdeğer hesaplamaları ile ilgili davranışları üzerinde incelemeler yapılması hedeflenmektedir. 


\section{KAYNAKLAR}

[1] Kass M, Witkin A, Terzopoulos D. Snakes: Active contour models. Int J Comput Vis. 1988;1(4):32131.

[2] Caselles V, Kimmel R, Sapiro G. Geodesic Active Contours. Int J Comput Vis. 1997;22(1):61-79.

[3] Hanbay K, Talu MF. A novel active contour model for medical images via the Hessian matrix and eigenvalues. Comput Math with Appl. 2018;75(9):3081-104.

[4] Zhang K, Song H, Zhang L. Active contours driven by local image fitting energy. Pattern Recognit. 2010;43(4):1199-206.

[5] Zhang K, Zhang L, Song H, Zhou W. Active contours with selective local or global segmentation: A new formulation and level set method. Image Vis Comput. 2010;28(4):668-76.

[6] Chan TF, Vese LA. Active contours without edges. IEEE Trans Image Process. 2001;10(2):266-77.

[7] Paragios N. Geodesic active contours and level sets for the detection and tracking of moving objects. IEEE Trans Pattern Anal Mach Intell. 2000;22(3):266-80.

[8] Min H, Xia L, Pan Q, Fu H, Wang H, Li H. Local features based level set method for segmentation of images with intensity inhomogeneity. Commun Comput Inf Sci. 2017;772:498-508.

[9] Duan Y, Peng T, Qi X. Active contour model based on LIF model and optimal DoG operator energy for image segmentation. Optik. 2020;202:163667.

[10] Li C, Kao CY, Gore JC, Ding Z. Implicit active contours driven by local binary fitting energy. In: Proceedings of the IEEE Computer Society Conference on Computer Vision and Pattern Recognition. Minneapolis; 2007. p. 1-7.

[11] Brown ES, Chan TF, Bresson X. Completely convex formulation of the Chan-Vese image segmentation model. Int $\mathbf{J}$ Comput Vis. 2012;98(1):103-21.

[12] Vese LA, Chan TF. A Multiphase Level Set Framework for Image Segmentation Using the Mumford and Shah Model. Int J Comput Vis 2002 503. 2002;50(3):271-93.

[13] Menon R V., Kalipatnapu S, Chakrabarti I. High speed VLSI architecture for improved region based active contour segmentation technique. Integration. 2021;77:25-37.

[14] Niu S, Chen Q, de Sisternes L, Ji Z, Zhou Z, Rubin DL. Robust noise region-based active contour model via local similarity factor for image segmentation. Pattern Recognit. 2017;61:104-19.

[15] Abdelsamea MM, Pitiot A, Grineviciute RB, Besusparis J, Laurinavicius A, Ilyas M. A cascadelearning approach for automated segmentation of tumour epithelium in colorectal cancer. Expert Syst Appl. 2019;118:539-52.

[16] Carmo M Do. Differential Geometry of Curves and Surfaces. Prentice-Hall, Englewood Cliffs, NJ; 1976.

[17] Cooley JW, Tukey JW. An algorithm for the machine calculation of complex Fourier series. Math Comput. 1965;19(90):297-301.
[18] Duhamel P, Vetterli M. Fast fourier transforms: A tutorial review and a state of the art. Signal Processing. 1990;19(4):259-99.

[19] Abdou IE, Pratt WK. Quantitative design and evaluation of enhancement/thresholding edge detectors. Proc IEEE. 1979;67(5):753-63. 